\title{
Choroidal evaluation in patients under alpha-lytic therapy
}

\author{
Maddalena De Bernardo ${ }^{1}$ (D) $\cdot$ Vincenzo Altieri $^{1} \cdot$ Alessia Coppola $^{1} \cdot$ Marco Gioia $^{1} \cdot$ Nicola Rosa ${ }^{1}$
}

Received: 6 April 2020 / Revised: 29 July 2020 / Accepted: 19 August 2020 / Published online: 2 September 2020

(C) The Author(s) 2020

\begin{abstract}
Purpose To detect any choroidal thickness (CT) change in patients after alpha-lytic drugs withdrawal that could help in the cataract surgery timing decision.

Methods Twenty-five eyes of 25 patients (mean age: $76 \pm 7$ years) under alpha-lytic therapy, and 25 eyes of 25 control subjects (CS) (mean age: $75 \pm 7$ years) without alpha-lytic therapy, both scheduled for cataract surgery in the fellow eye, were included in this observational, prospective, non-randomized study. All patients underwent EDI-OCT during the first preoperative visit and approximately 1 month (range 28-31 days) after alpha-lytic withdrawal. In the CS group, the OCT during preoperative visit and approximately 1 month after (range 28-31 days) the first examination was performed. Data normality with Kolmogorov-Smirnov test was checked and statistical evaluation with the Wilcoxon-signed rank test was performed.

Results The mean subfoveal CT was $224 \pm 79.7 \mu \mathrm{m}$ during therapy and $217 \pm 70.4 \mu \mathrm{m}$ after withdrawal; $1.5 \mathrm{~mm}$ nasally from the fovea CT was $198 \pm 83.8 \mu \mathrm{m}$ and $194 \pm 82.8 \mu \mathrm{m}$, respectively; and $1.5 \mathrm{~mm}$ temporally from the fovea CT was $217 \pm 55.9 \mu \mathrm{m}$ and $205 \pm 54.4 \mu \mathrm{m}$, respectively. A statistically significant reduction $(p<0.05)$ in all the 3 measured CT points was found. In the CS no significant changes were detected $(p>0.05)$.

Conclusion No severe floppy iris syndrome was detected at the time of surgery. In these patients, CT decrease could be an important sign for cataract surgery timing decision.
\end{abstract}

Keywords Choroidal thickness $\cdot$ IFIS $\cdot$ Cataract surgery $\cdot$ OCT $\cdot$ Alpha-lytic therapy

\section{Introduction}

Cataract represents the leading cause of blindness worldwide [1]. Today, due to the phacoemulsification techniques and the improvements in intraocular lens (IOL) calculations, cataract surgery is considered one of the most successful procedures in ophthalmology [2].

An adequate pupillary dilatation and the iris stability are among the reasons that make this surgery successful.

Sympathetic system, through noradrenaline release, induces radial iris muscle contraction and subsequent pupil dilation (mydriasis). Unfortunately, several drugs, such as selective $\alpha 1$ adrenergic receptor antagonists (ARA) inhibitors, can

Maddalena De Bernardo

mdebernardo@unisa.it

1 Department of Medicine, Surgery and Dentistry "Scuola Medica Salernitana", University of Salerno, via S. Allende,

84081 Baronissi, Salerno, Italy complicate cataract surgery, inducing miosis with iris stroma surging and billowing. Even with normal intraocular fluid flows and despite well-constructed wounds, iris could prolapse through surgical incisions. This phenomenon has been described with the name of intraoperative floppy iris syndrome (IFIS) [3].

Ophthalmologists must be aware of IFIS because it is associated with high rates of intraoperative complications, such as iris prolapse, capsulorhexis tear, iris trauma, anterior chamber hemorrhage, zonula dehiscence, posterior capsule rupture, and vitreous loss, as well as postoperative complications, including intraocular pressure elevation and cystoid macular edema $[4,5]$.

To try to avoid the IFIS onset, the withdrawal of selective $\alpha 1$ ARA inhibitors before surgery has been suggested. Unfortunately, such discontinuation is not always effective and no objective preoperative signs, which help to forecast the success in avoiding IFIS have been described.

As the whole uvea could be involved in the drug-induced modifications, the purpose of this study was to check if such a withdrawal could produce choroidal thickness (CT) changes. 


\section{Key messages}

- Choroidal thickness is known to be increased in patients assuming alpha-lytic therapy

- The present study proves the choroidal thickness reduction after alpha-lytic drugs withdrawal

- This sign could be taken into account in deciding cataract surgery timing to avoid IFIS

\section{Methods}

In the present observational, prospective, non-randomized study, patients scheduled for cataract surgery in the Eye Department of the University of Salerno, taking alpha-lytic therapy, and a control group were included. The study was consistent with the tenets of the Declaration of Helsinki; institutional ethics committee approval and informed consent were obtained from all participants. Patients affected by corneal leukomas, diabetes, maculopathy, central serous chorioretinopathy, and optic neuropathy were excluded. Twenty-five eyes of 25 consecutive patients with a mean age of $76 \pm 7$ years, ranging from 58 to 85 years, were evaluated, of whom twenty-four male patients with a previous diagnosis of Benign Prostatic Hypertrophy (BPH), whose urinary symptoms were controlled by alpha-lytic therapy (twelve patients took Tamsulosin, seven Alfuzosin and others five Silodosin) and one female with Arterial Hypertension (AH), controlled by Doxazosin. For comparison, a control group of 25 patients with a mean age of $75 \pm 7$ years, ranging from 61 to 86 years that were not on alpha-lytic therapy, was utilized.

In both groups, because of dense lens opacities that could cause fictitious and inaccurate results, or possible artifacts induced by surgery, the fellow eyes were examined, whereas the operated eyes were excluded. The day of preoperative visit, all patients underwent complete eye examination, including uncorrected and best spectacle corrected visual acuity, anterior segment evaluation, intraocular pressure (IOP), fundus examination, axial length (AL) measurement with an IOLMaster (5.4.4.0006; Carl Zeiss Meditec AG), and OCT examination with Heidelberg Spectralis OCT using EDI in $840 \mathrm{~nm}$ (Software version 5.3; Spectralis SD-OCT; Heidelberg Engineering, Heidelberg, Germany). Scans were acquired using a single horizontal line scan, with a scanning angle of 308 and consisted of 36 frames per B-scan using the average real time mode (ART). Only scans through the fovea and images with a high signal-to-noise ratio (minimum of $20 \mathrm{~dB}$ ) were included and used for the CT evaluation. In order to reduce the IFIS risk, after consultation with urologist or cardiologist, patients were asked to discontinue alpha-lytic therapy and not to change their lifestyles or other therapies. The day of the surgery, performed approximately 1 month later (range $28-$ 31 days), the OCT examination was repeated. Utilizing the OCT software, the measurements were obtained by an expert examiner, not aware of the patients' distribution. A line connecting the RPE outer edge and the scleral inner edge was drawn, being perpendicular to the line tangential to the foveal contour. The measurements were performed at subfoveal level, at $1.5 \mathrm{~mm}$ nasally and temporally to the fovea. All data were analyzed with SPSS Software (IBM SPSS Statistics version 25). The normal data distribution was assessed with Kolmogorov-Smirnov test. Sample size was determined by maximizing the statistical power. The analysis was performed by using $\mathrm{G}^{*}$ Power3.1 software [6]. A difference between two dependent means (matched pairs) Wilcoxon rank test was computed. Input data were the following: $\alpha$ was set at $0.05,1-\beta$ was set at 0.80 , and effect size was set as medium at around 0.6. Results were the following: non-centrality parameter $\delta=2.932$, critical $t=2.069, \mathrm{DF}=22.873$, actual power $=0.80$, and total sample size $=25$.

Table 1 Choroidal thickness characteristics of patients before and after therapy withdrawal

\begin{tabular}{lllll}
\hline & & $\begin{array}{l}\text { Preoperative } \\
\text { visit } \\
{[\mu \mathrm{m}]}\end{array}$ & $\begin{array}{l}\text { After therapy withdrawal } \\
{[\mu \mathrm{m}]}\end{array}$ & \\
\hline Fovea & Mean & 224.1 & 217 & 0.025 \\
& SD & 79.7 & 80.4 & \\
& Median & 229 & 219 & 0.039 \\
& Range & $62-387$ & $53-392$ & \\
Nasal & Mean & 198.2 & 193.8 & 0.003 \\
& SD & 83.8 & 82.8 & \\
& Median & 185 & 186 & \\
& Range & $62-375$ & $74-357$ & \\
& Mean & 217.1 & 204.7 & 54.4 \\
& SD & 55.9 & 208 & \\
& Median & 210 & $58-301$ & \\
& Range & $90-312$ & &
\end{tabular}

Mean, standard deviation (SD), median and range of choroidal thickness evaluated at the fovea, at $1.5 \mathrm{~mm}$ nasally and $1.5 \mathrm{~mm}$ temporally from the fovea at the preoperative visit and 1 month after alpha-lytic therapy withdrawal 
Table 2 Choroidal thickness characteristics of control group.

\begin{tabular}{lllll}
\hline & & $\begin{array}{l}\text { Preoperative visit } \\
{[\mu \mathrm{m}]}\end{array}$ & $\begin{array}{l}\text { One month later } \\
{[\mu \mathrm{m}]}\end{array}$ & $p$ \\
\hline Fovea & Mean & 187.3 & 182.1 & 0.113 \\
& SD & 68.8 & 63.8 & \\
& Median & 194 & 189 & \\
& Range & $52-326$ & $56-306$ & 0.647 \\
Nasal & Mean & 148.1 & 146.0 & \\
& SD & 65.2 & 58.8 & 0.667 \\
& Median & 144 & 136 & \\
& Range & $20-291$ & $32-266$ & \\
& Mean & 168.2 & 169.8 & \\
& SD & 59.5 & 58.5 & 153 \\
& Median & 161 & $69-307$ & \\
& Range & $52-304$ & &
\end{tabular}

Mean, standard deviation (SD), median and range of choroidal thickness evaluated at the fovea, at $1.5 \mathrm{~mm}$ nasally and $1.5 \mathrm{~mm}$ temporally from the fovea at the pre-operative visit and 1 month later in the control group

\section{Results}

The $\mathrm{CT}$ in different zones before and 1 month after the alphalytic therapy withdrawal is shown in Table 1 and in Figs. 1, 2, $3,4 \mathrm{a}, \mathrm{b}$. The same values in the control group are shown in Table 2 and in Figs. 5, 6, 7, 8a, b. The data, analyzed with the
Wilcoxon signed rank test, underlined a statistically significant $\mathrm{CT}$ reduction 1 month after therapy withdrawal $(p=$ $0.05)$. No significant changes in the control group have been detected (Table 2).

Due to the small number of patients, and the absence of statistically significant difference in the AL between the two groups, evaluated with Mann-Whitney test (Table 3), they were not divided in subgroups according to $\mathrm{AL}$ or refractive errors.

\section{Discussion}

Alpha-lytic therapy is a widely used medication for BPH treatment that has been shown to cause IFIS, which involves the anterior uveal portion. In rabbit eyes, choroidal vasodilation and reduced vascular tone related to $\alpha_{1}$ adrenoreceptor use were detected [7]. In two case reports a choroidal detachment in patients assuming Tamsulosin was described $[8,9]$.

The EDI-OCT, introduced in 2008, allows precise in vivo CT measurements and represents the most used method for choroidal imaging evaluation. It does not require SD-OCT hardware changes [10], because the software shifts the zerodelay line below, rather than above, obtaining inverted images. In this way, the operator can capture EDI-OCT images more easily because the image is now direct, rather than inverted. However, this technique does not allow the automatic CT measurement, so the operators have to manually draw the line to measure it [11]. In clinical practice, $\mathrm{CT}$ detection is

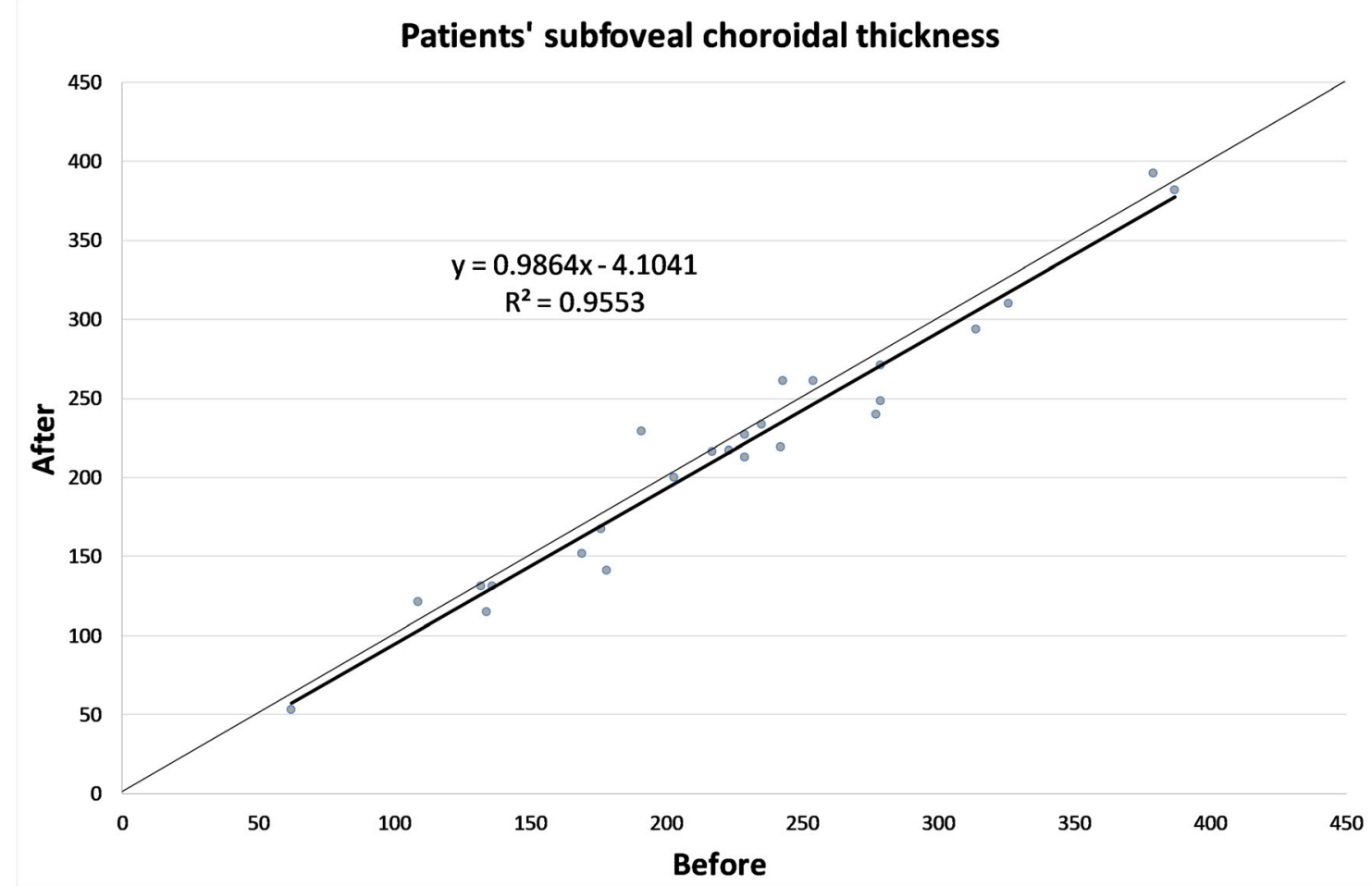

Fig. 1 Patients' choroidal thickness at the subfoveal level before and after alpha-lytic therapy withdrawal 


\section{Patients' nasal choroidal thickness}

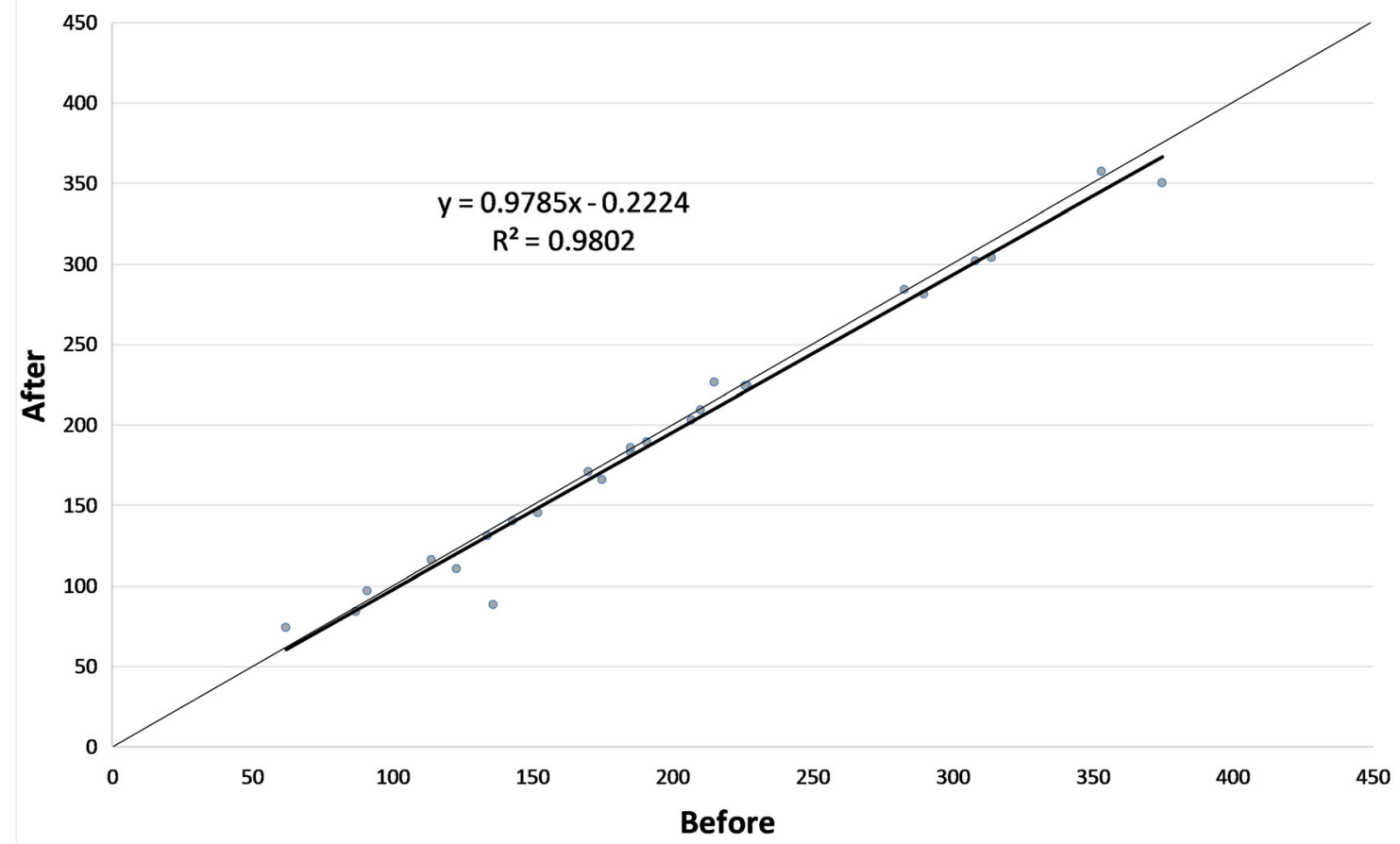

Fig. 2 Patients' choroidal thickness at $1.5 \mathrm{~mm}$ nasally from the fovea before and after alpha-lytic therapy withdrawal

the most useful application for EDI-OCT choroidal imaging. Two studies on CT changes alpha-lytic therapy related showed different results $[12,13]$.
Sari at al. [12] utilizing an EDI-OCT (ZEISS Cirrus HDOCT 4000) in 29 eyes of 29 patients with new BPH diagnosis before and 3 months after tamsulosin intake attempted to

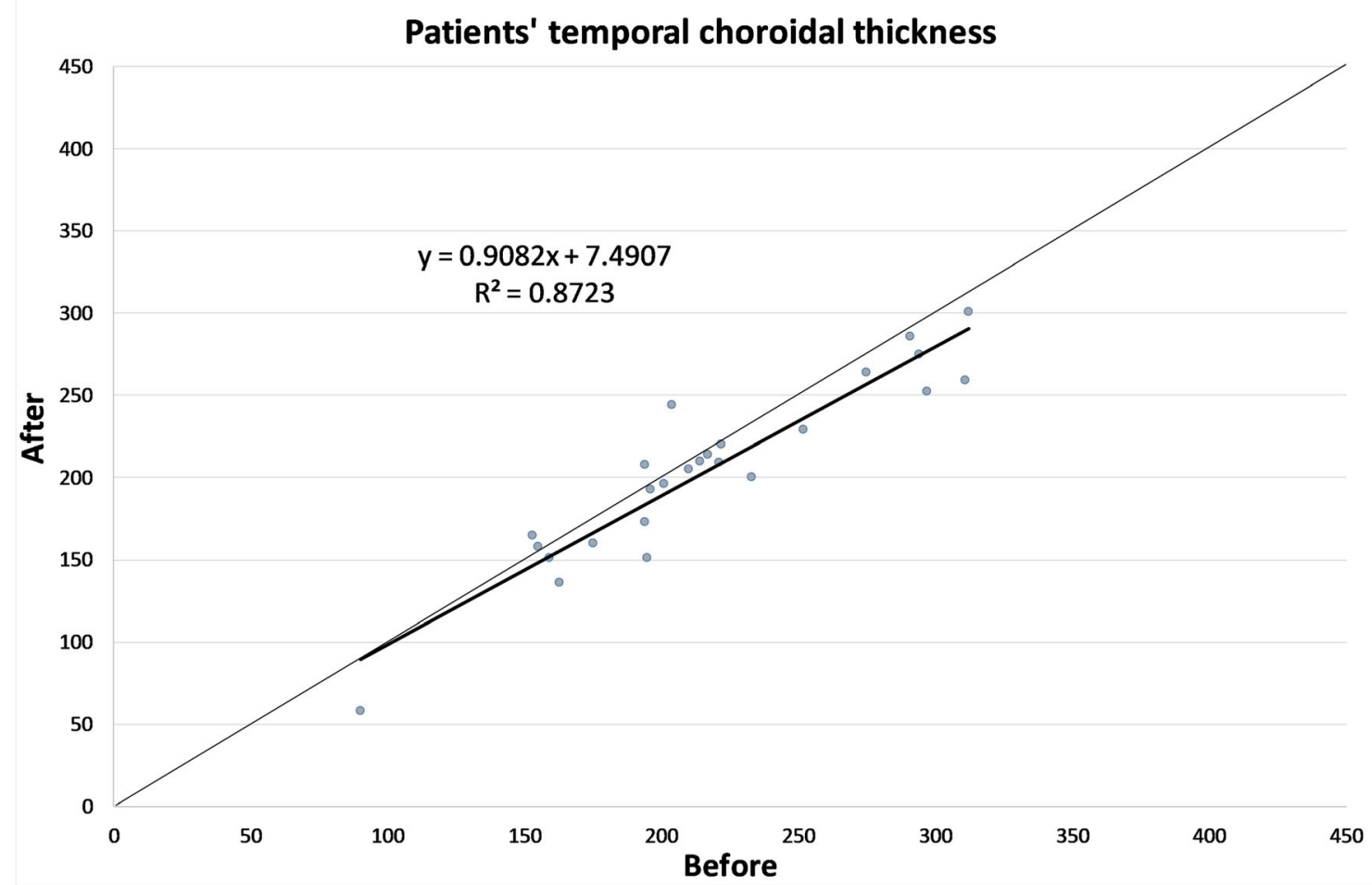

Fig. 3 Patients' choroidal thickness at $1.5 \mathrm{~mm}$ temporally from the fovea before and after alpha-lytic therapy withdrawal 

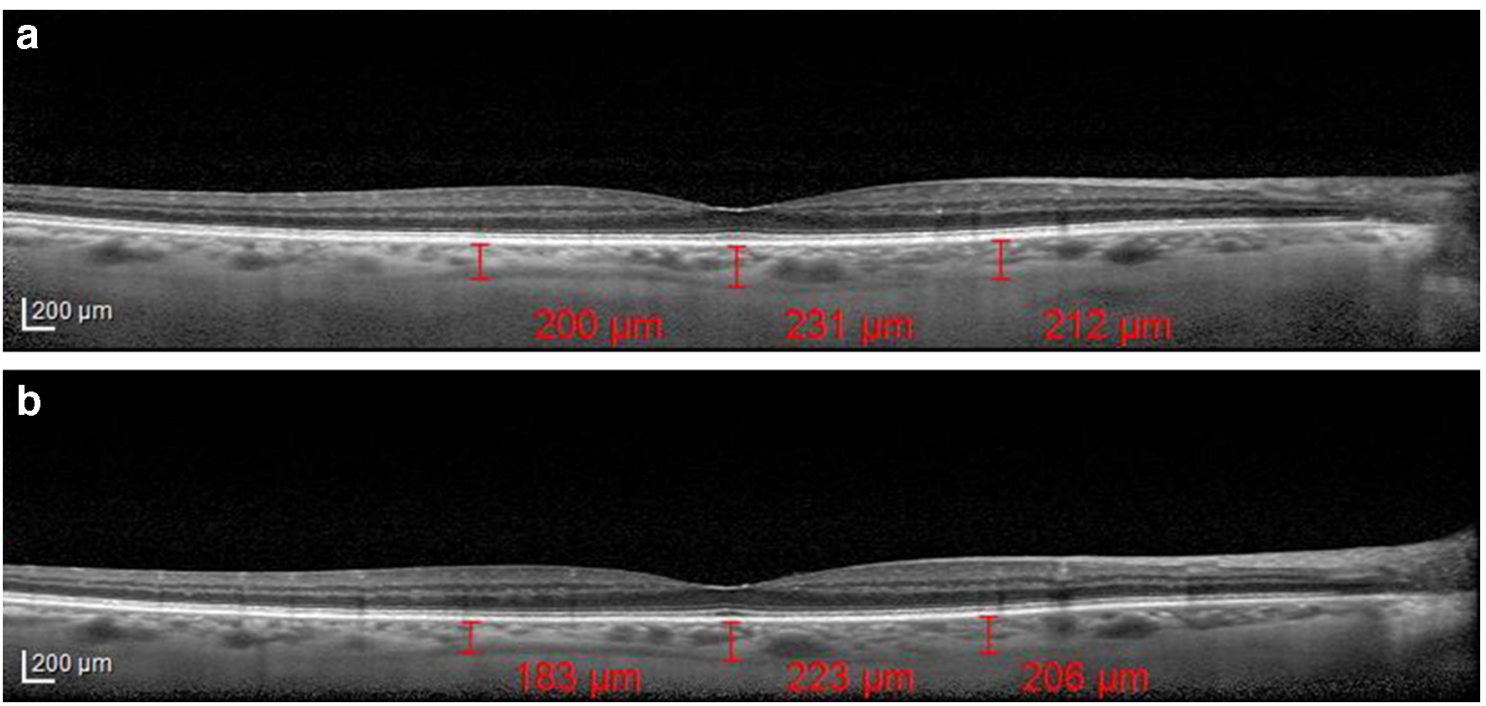

Fig. 4 a Choroidal thickness evaluated at the sub-foveal level, at $1.5 \mathrm{~mm}$ nasally and temporally from the fovea in a patient under alpha-lytic treatment. b Choroidal thickness evaluated at the subfoveal level, at $1.5 \mathrm{~mm}$

check any drug-induced choroidal change. CT at the subfoveal level and at $750 \mu \mathrm{m}$ nasally and temporally from the fovea was measured. All 3 observed points showed a significant thickness increase, and a vasomotor effect was suggested. In a comment to this paper, Yolcu et al. [14] proposed that tamsulosin affinity to melanin leads to its choroidal sequestration and its $\alpha 1 \mathrm{~A}$ adrenoreceptor-blocking activity leads to $\mathrm{CT}$ increase. nasally and temporally from the fovea in the same patient 1 month after alpha-lytic therapy withdrawal

Dogan et al. [13] in 2017 evaluated 63 right eyes of 63 patients diagnosed with BPH (32 taking alfuzosin and 31 tamsulosin) with EDI-OCT (ZEISS Cirrus HD-OCT 4000). The measurements were performed manually, using a dedicated software, at the subfoveal level and at $3 \mathrm{~mm}$ nasally and temporally from the fovea. Contrary to the previous one, a statistically significant choroidal thickening was only observed in patients treated with Alfuzosin.

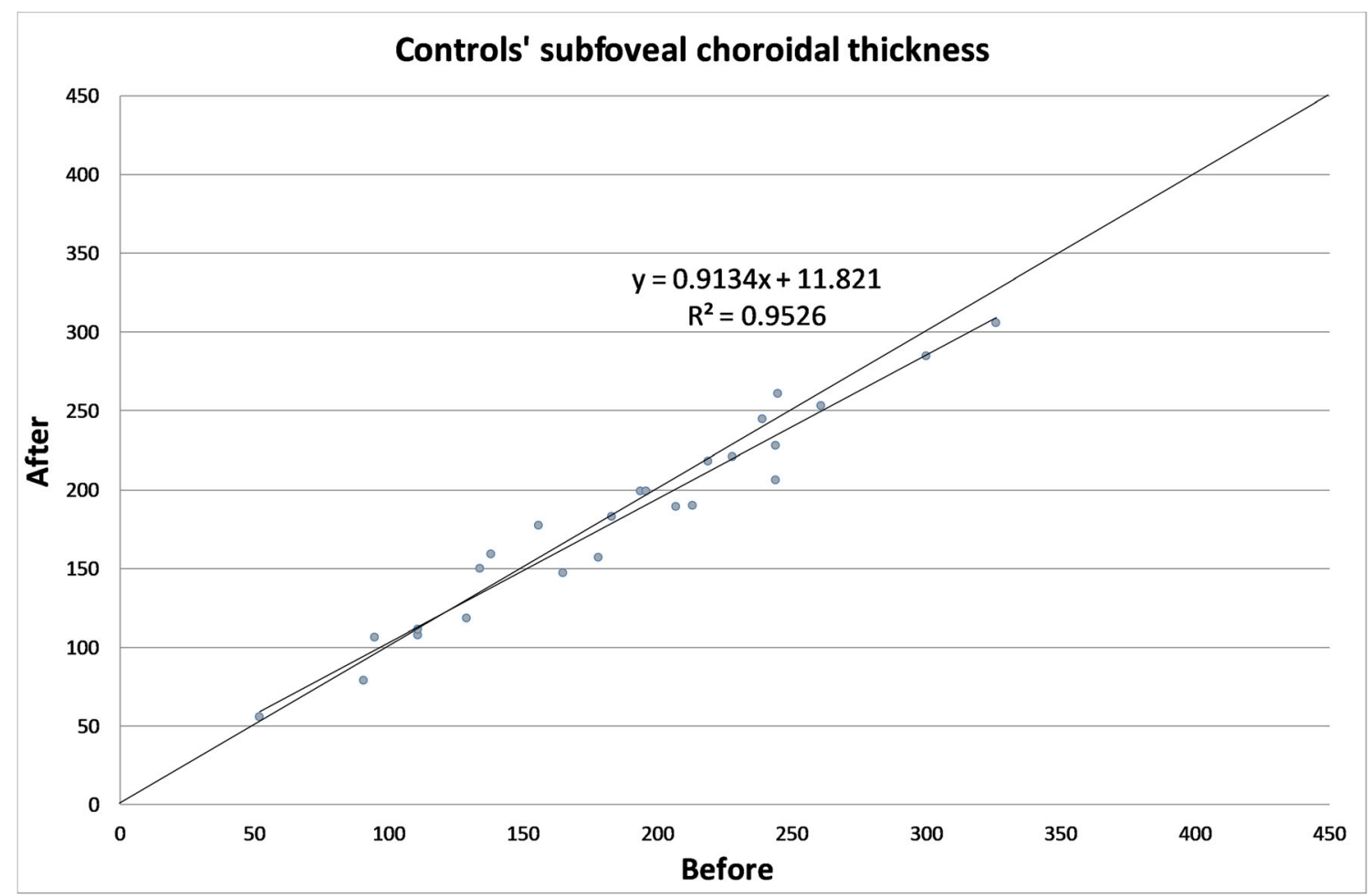

Fig. 5 Control subject choroidal thickness at the subfoveal level at the first visit and 1 month later 


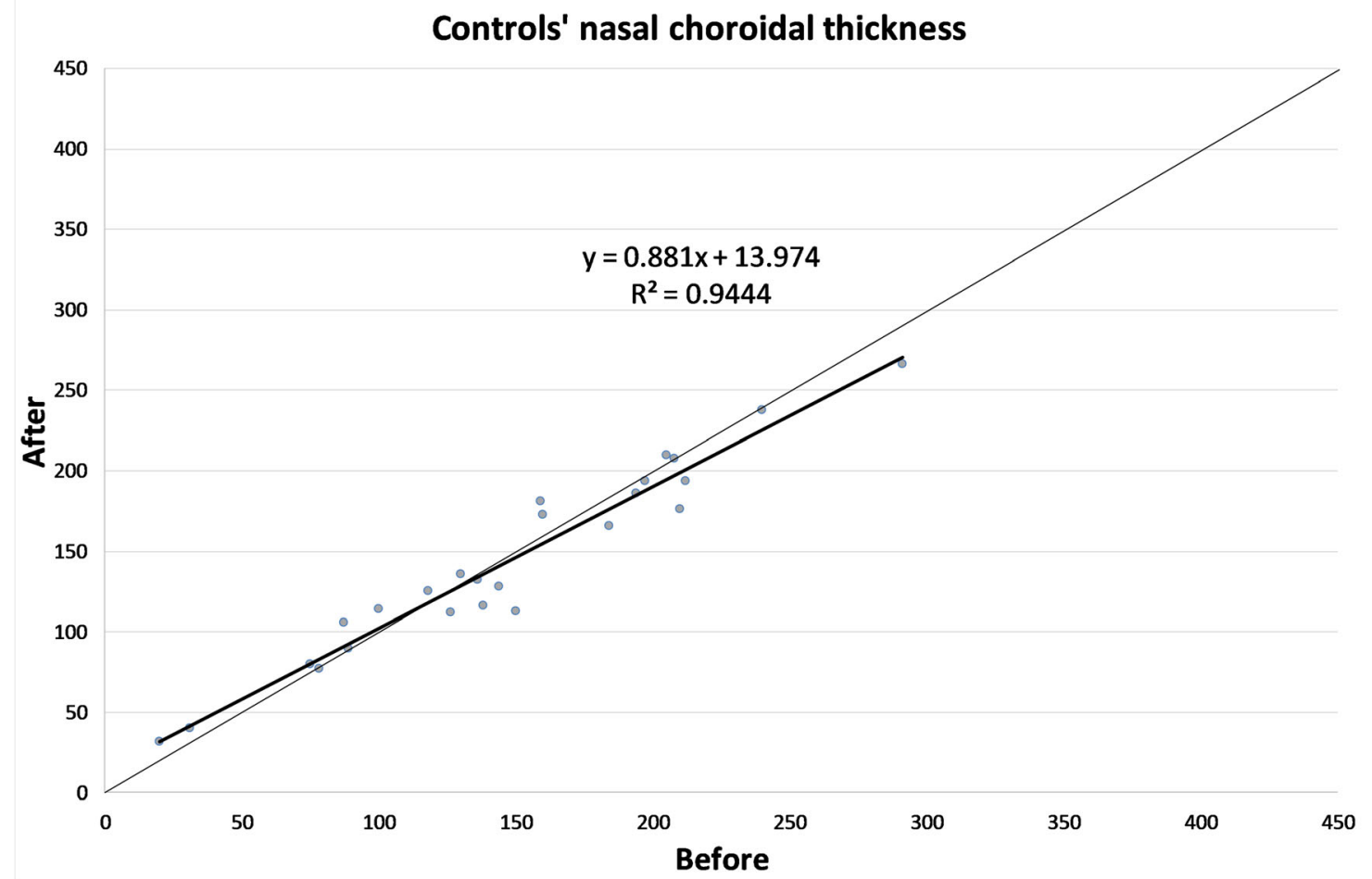

Fig. 6 Control subject choroidal thickness at $1.5 \mathrm{~mm}$ nasally from the fovea at the first visit and 1 month later

The differences between these two papers could be related to the measurement points, in one case $750 \mu \mathrm{m}$ and in the other one, $3 \mathrm{~mm}$ from the fovea.
This hypothesis seems to be supported by the statistically significant $\mathrm{CT}$ reduction at $1.5 \mathrm{~mm}$ nasally and temporally from the fovea after drug withdrawal, found in the present study.

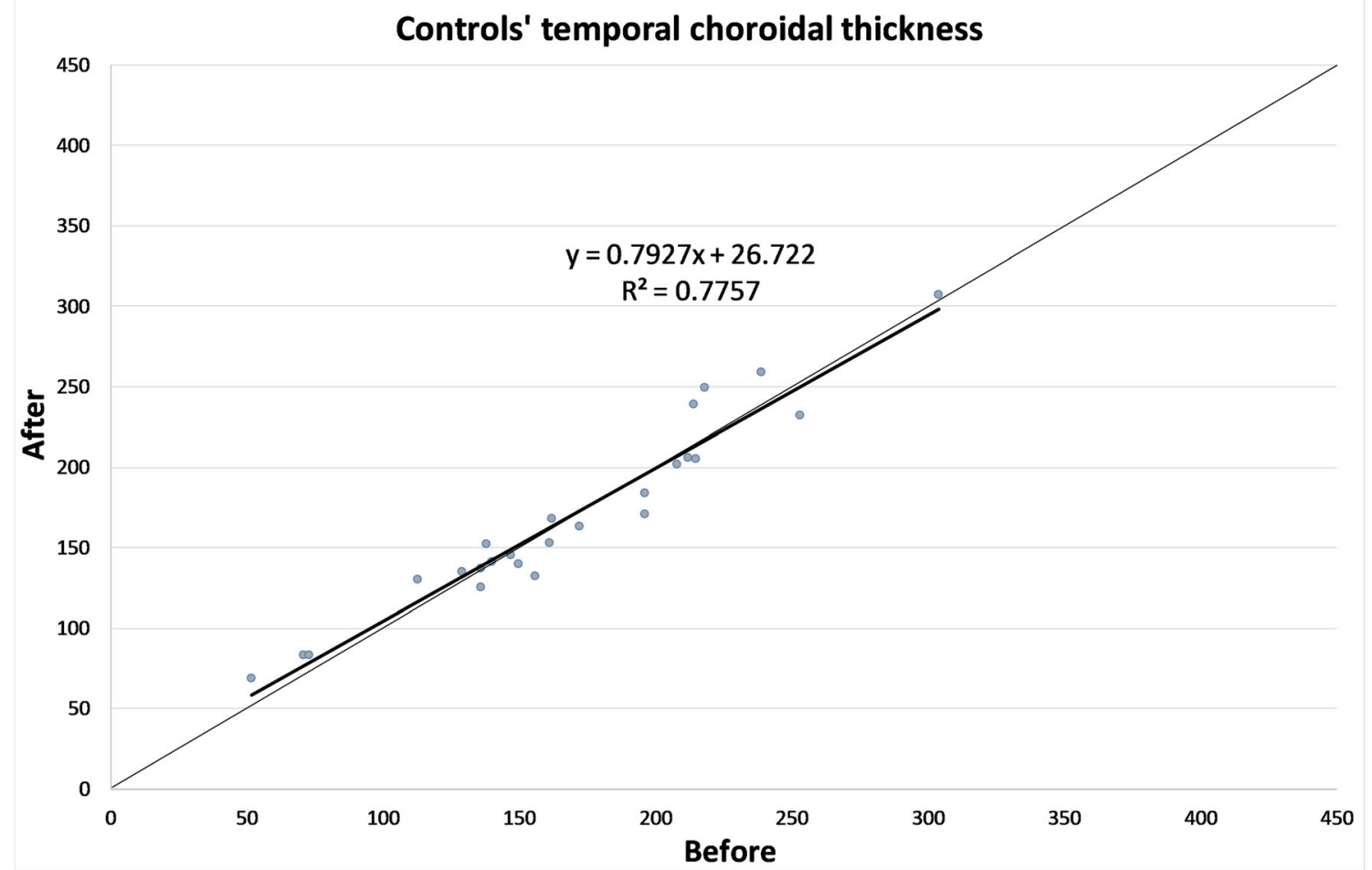

Fig. 7 Control subject choroidal thickness at $1.5 \mathrm{~mm}$ temporally from the fovea at the first visit and 1 month later 

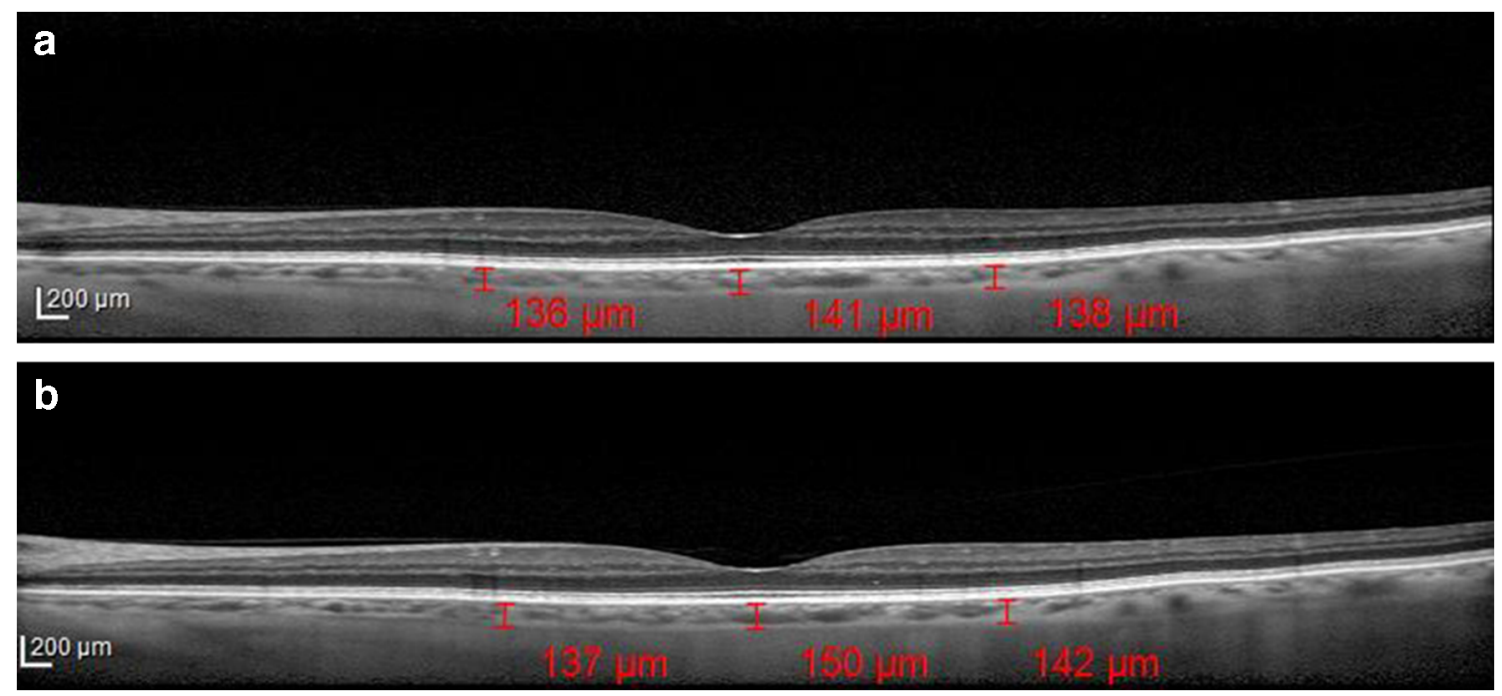

Fig. 8 (a) Choroidal thickness evaluated at the subfoveal level, at $1.5 \mathrm{~mm}$ nasally and temporally from the fovea in a control subject at the first visit. b Choroidal thickness evaluated at the subfoveal level, at $1.5 \mathrm{~mm}$ nasally and temporally from the fovea in the same subject, 1 month later

However, in our opinion, the main importance of the present study is the finding of a CT decrease when alpha-lytic therapy was discontinued.

In this study CT was not related to refractive errors of the examined patients. At the first sight, this could be seen as a limitation, but there are mainly two reasons for this choice. First of all, some lens opacities were present also in the fellow eye, but, more importantly, we decided to analyze the AL instead of refractive error because previous studies showed that CT presents a significant relationship with AL, whereas borderline significance was seen with the refractive errors [15-17].

The CT evaluation might be the key for the surgery timing in patients with IFIS risk. A smaller CT reduction might be associated with alpha-lytic therapy long lasting effects on the whole uvea, hence the surgeons could delay procedures until no residual drug effects are present, making the CT measurements an important step for this challenging problem

Table 3 Axial length characteristics of the two groups

\begin{tabular}{lll}
\hline & $\begin{array}{l}\text { Patients under } \\
\text { alpha-lytic therapy } \\
{[\mathrm{mm}]}\end{array}$ & $\begin{array}{l}\text { Control group } \\
{[\mathrm{mm}]}\end{array}$ \\
\hline Mean & 23.51 & 23.52 \\
SD & 0.92 & 1.51 \\
Median & 23.52 & 23.15 \\
Range & $21.17-25.41$ & $21.72-28.76$ \\
P & 0.294 & \\
\hline
\end{tabular}

Mean, standard deviation (SD), median and range of the axial length of patients under alpha-lytic therapy and control group resolution. In the light of our findings, to establish the landmark that could predict the IFIS absence during surgery, further studies comparing the CT decrease and the IFIS presence during surgery are needed.

Funding Open access funding provided by Università degli Studi di Salerno within the CRUI-CARE Agreement.

Data availability The data used to support the findings of this study are available from the corresponding author upon request.

\section{Compliance with ethical standards}

Conflicts of interest/competing interest No conflicting relationship exists for any author.

Ethics approval The study was approved by the institutional research ethics committee, Cometico Campania Sud, Italy, (prot.n $\left.{ }^{\circ} 16,544\right)$. The study was performed in accordance with the ethical standards as laid down in the 1964 Declaration of Helsinki and its later amendments.

Consent to participate Informed consent was obtained from all individual participants included in the study.

Code availability Not applicable.

Open Access This article is licensed under a Creative Commons Attribution 4.0 International License, which permits use, sharing, adaptation, distribution and reproduction in any medium or format, as long as you give appropriate credit to the original author(s) and the source, provide a link to the Creative Commons licence, and indicate if changes were made. The images or other third party material in this article are included in the article's Creative Commons licence, unless indicated otherwise in a credit line to the material. If material is not included in the article's Creative Commons licence and your intended use is not permitted by statutory regulation or exceeds the permitted use, you will need to obtain permission directly from the copyright holder. To view a copy of this licence, visit http://creativecommons.org/licenses/by/4.0/. 


\section{References}

1. Prokofyeva E, Wegener A, Zrenner E (2013) Cataract prevalence and prevention in Europe: a literature review. Acta Ophthalmol 91: 395-405. https://doi.org/10.1111/j.1755-3768.2012.02444.x

2. De Bernardo M, Salerno G, Cornetta P, Rosa N (2018) Axial length shortening after cataract surgery: new approach to solve the question. Transl Vis Sci Technol 7:34. https://doi.org/10.1167/tvst.7.6. 34

3. Chang DF, Campbell JR (2005) Intraoperative floppy iris syndrome associated with tamsulosin. J Cataract Refract Surg 31:664-673. https://doi.org/10.1016/j.jcrs.2005.02.027

4. Pedut Kloizman T, Shehadeh Mashour R (2016) Cataract surgery complications in males treated with alpha-1 antagonists for benign prostatic hyperplasia. Harefuah 155:542-546

5. Haridas A, Syrimi M, Al-Ahmar B, Hingorani M (2013) Intraoperative floppy iris syndrome (IFIS) in patients receiving tamsulosin or doxazosin-a UK-based comparison of incidence and complication rates. Graefes Arch Clin Exp Ophthalmol 251: 1541-1545. https://doi.org/10.1007/s00417-013-2260-4

6. Faul F, Erdfelder E, Lang AG, Buchner A (2007) G*Power 3: A flexible statistical power analysis program for the social,behavioral, and biomedical sciences. Behav Res Methods 39:175-191. https:// doi.org/10.3758/BF03193146

7. Kiel JW, Lovell MO (1996) Adrenergic modulation of choroidal blood flow in the rabbit. Invest Ophthalmol Vis Sci 37:673-679

8. Kerimoglu H, Zengin N, Ozturk B, Gunduz K (2010) Unilateral chemosis, acute onset myopia and choroidal detachment following the use of tamsulosin. Acta Ophthalmol 88:20-21. https://doi.org/ 10.1111/j.1755-3768.2008.01503.x

9. Shapiro BL, Petrovic V, Lee SE, Flach A, McCaffery S, O'Brien JM (2007) Choroidal detachment following the use of tamsulosin (Flomax). Am J Ophthalmol 143:351-353. https://doi.org/10.1016/ j.ajo.2006.09.032

10. Spaide RF, Koizumi H, Pozonni MC (2008) Enhanced depth imaging spectral-domain optical coherence tomography. Am J
Ophthalmol 146:496-500. https://doi.org/10.1016/j.ajo.2008.05. 032

11. Wong IY, Koizumi H, Lai WW (2011) Enhanced depth imaging optical coherence tomography. Ophthalmic Surg Lasers Imaging 42(Suppl):S75-S84. https://doi.org/10.3928/15428877-2011062707

12. Sari E, Sari ES, Yazici A, Koç A, Bulbul E, Koytak A, Ermis SS, Erol MK (2015) The effect of systemic tamsulosin hydrochloride on choroidal thickness measured by enhanced depth imaging spectral domain optical coherence tomography. Curr Eye Res 40:10681072. https://doi.org/10.3109/02713683.2014.971935

13. Dogan M, Kutluksaman B, Keles I, Karalar M, Halat AO (2017) The effects of systemic alfuzosin and tamsulosin hydrochloride on choroidal thickness and pupil diameter sizes in cases with benign prostatic hyperplasia. Curr Eye Res 42:1638-1643. https://doi.org/ 10.1080/02713683.2017.1359306

14. Yolcu U, Ilhan A, Uzun S (2016) The effect of systemic Tamsulosin hydrochloride on Choroidal thickness measured by enhanced depth imaging spectral domain optical coherence tomography. Curr Eye Res 41:999. https://doi.org/10.3109/02713683. 2015.1069854

15. Ikuno Y, Kawaguchi K, Nouchi T, Yasuno Y (2010) Choroidal thickness in healthy Japanese subjects. Invest Ophthalmol Vis Sci 51:2173-2176. https://doi.org/10.1167/iovs.09-4383

16. Li XQ, Larsen M, Munch IC (2011) Subfoveal choroidal thickness in relation to sex and axial length in 93 Danish University students. Invest Ophthalmol Vis Sci 52:8438-8441. https://doi.org/10.1167/ iovs.11-8108

17. Michalewski J, Michalewska Z, Nawrocka Z, Bednarski M, Nawrocki J (2014) Correlation of choroidal thickness and volume measurements with axial length and age using swept source optical coherence tomography and optical low-coherence reflectometry. Biomed Res Int 2014:639160. https://doi.org/10.1155/2014/ 639160

Publisher's note Springer Nature remains neutral with regard to jurisdictional claims in published maps and institutional affiliations. 